\title{
Profile of neonates born with congenital birth defects in a tertiary care hospital of North India: An observational study
}

\author{
Abhilasha Sinha ${ }^{a}$, Shalini Tripathi ${ }^{\text {b, }}$, Nitu Nigam ${ }^{c}$, Mala Kumar ${ }^{a}$, S.N. Singh ${ }^{a}$ \\ ${ }^{a}$ Department of Pediatrics, King George's Medical University, Uttar Pradesh, India \\ ${ }^{\mathrm{b}}$ Department of Pediatrics, King Georges Medical University, Lucknow, Uttar Pradesh, 226003, India \\ c Department of Cytogentics (CFAR), King George's Medical University, Uttar Pradesh, India
}

\section{A R T I C L E I N F O}

\section{Keywords:}

Congenital birth defect

Incidence

Live births

Outcome

Risk factors

\begin{abstract}
A B S T R A C T
Objectives: India shares largest burden of congenital birth defects (CBDs) in the world. There is paucity of data on the CBDs in our region of the country.

Methods: This was a hospital based observational study to find incidence, risk factors and outcome of CBDs among live neonates.

Results: Of 7,075 babies, 92 had 124 CBDs, making the incidence 1.3\%. The system predominantly involved was musculoskeletal system (52.2\%) followed by central nervous system (28.3\%), genitourinary system (26.1\%). Among the single CBDs, congenital talipes equino varus (27.4\%) was the commonest followed by spina bifida $(11.2 \%)$ and cleft palate (6.4\%). The significant factors associated with CBD were no antenatal visits $(\mathrm{p}=0.041)$, TORCH and/or VDRL positivity $(\mathrm{p}=0.023)$, gestational diabetes mellitus (GDM) $(\mathrm{p}=0.007)$, hypertension $(\mathrm{p}=$ 0.090 ), consanguinity ( $\mathrm{p}=0.03$ ), no intake of folic acid ( $\mathrm{p}=0.015)$. Of these, factors found significant on logistic regression were GDM (OR 3.44; $\mathrm{p}=0.018$ ), maternal hypertension (OR 4.88; $\mathrm{p}=0.011$ ), consanguinity (OR 13.55; $\mathrm{p}=0.028$ ) and no intake of iron/folic acid (OR 5.53; $\mathrm{p}=0.001$ ). Of the 92 neonates with CBD, 44 (47.8\%) were discharged, 28 (30.5\%) expired, $20(21.7 \%)$ left against medical advice.

Conclusion: Incidence of CBD was comparable to previous Indian studies. Consanguinity, no intake of folic acid, maternal hypertension and GDM were associated risk factors. About half neonates with CBD expired or left against medical advice. This shows dismal outcome of neonates with CBD in this region.
\end{abstract}

\section{Introduction}

According to March of Dimes (MOD) global report on birth defects, 7.9 million births occur annually worldwide with serious birth defect. $94 \%$ of these births defects occur in low-and middle-income countries (LMIC).In India, out of every 100 babies born annually, 6 to 7 have a $\mathrm{CBD}$, translating to 1.7 million (MOD, 2006). ${ }^{1}$ The recent studies from India show the incidence as $0.66 \%$ to $4.08 \%$. In developed world, CBDs affect one in every 33 babies born each year. It accounts for $20 \%$ of all infant deaths in United States. ${ }^{2}$

According to Rashtriya Bal Swasthya Karyakram, India with a birth cohort of 26 million annually accounts for highest share of CBD globally. Here, CBD mortality (8.6\%) ranked as the fourth leading cause of neonatal death, after neonatal preterm birth (27.7\%), neonatal encephalopathy due to birth asphyxia and trauma (14.5\%), and lower respiratory infections $(11 \cdot 0 \%) .{ }^{3}$ According to joint World Health Organization and MOD meeting report, $7 \%$ of all neonatal mortality and 3.3 million under five deaths have been attributed to CBDs. ${ }^{4}$

A recent study by Ujagare D et al. (2021) about birth defect mortality in India from 1997-2017, indicate that birth defects caused 37,104 deaths in the early neonatal period and 27,120 deaths in the postneonatal period in 2017 in India. These rates were double and five times higher when compared with the whole group of middle- and highincome countries respectively. ${ }^{5}$ In LMIC, including India, there is transition among causes of infant and child mortality. With the control of infectious causes in India, mortality due to congenital anomalies has been increased. ${ }^{6}$ SEAR-NBBD database has been established by WHO and $\mathrm{CDC}$ for supporting surveillance of birth defects and has supported

\footnotetext{
* Corresponding author.

E-mail addresses: sinha.abhilasha2@gmail.com (A. Sinha), shaliniawasthi@kgmcindia.edu (S. Tripathi), nigamnitu@gmail.com (N. Nigam), mala_lko@yahoo.co, in (M. Kumar), drsn.singh@rediffmail.com (S.N. Singh).

URL: http://shaliniawasthi@kgmcindia.edu (S. Tripathi).
} 
hospital-based surveillance in the countries. By now more than 3 million births have been reported from more than 150 hospitals in the Region including more than 3000 babies with birth defects. Folic acid deficiency and rubella infection were found to be important risk factors. ${ }^{7}$

As per National family health survey-3 (NFHS-3), $22.8 \%$ female did not receive any antenatal care in India. ${ }^{8}$ According to MODS report, about $70 \%$ of CBDs can be prevented by utilization of basic resources and low cost primary strategies. ${ }^{1}$

Our hospital is the largest public sector hospital of this region of country. Also very limited data is available on burden of CBDs in this region of the country. Therefore we conducted this study to know the incidence of CBDs and its associated maternal perinatal risk factor and outcome among live newborns.

\section{Methods}

This is hospital based observational cross sectional study conducted at a tertiary care teaching hospital for a period of one year. All live neonates were screened for CBDs, at birth and before discharge from the hospital. Ethical clearance was obtained from the institutional ethical committee. Written informed consent was obtained from the parents of participants. An equal number of healthy gestational age and sex matched neonates were enrolled as controls. Still born neonates with or without CBDs were not included in the study. Neonates with metabolic disorders and whose parents did not give consent were excluded.

The neonates were examined systematically for the presence of CBDs at birth and every day during postnatal ward round till discharge. The CBDs were classified according to the international classification of disease-10 (ICD-10) ${ }^{9}$ and the incidence of CBDs among live newborns was calculated. System wise classification of CBD was also done.

The detailed characteristics of the CBD cases like birth weight, sex, gestational age, singleton or multiple births, mode of delivery were noted. For risk factor assessment, all relevant neonatal and maternal details were noted. The baseline demographic maternal details like -age, parity, weight, residence, education level, occupation, antenatal care, previous history of abortion and/or CBDs, invitro fertilization (IVF) conception and intake of iron and folic acid during conception was noted. Pregnancy related disorders like pregnancy induced hypertension, gestational diabetes mellitus (GDM), TORCH infections, were also noted. Maternal comorbidities like chronic hypertension, diabetes mellitus, anemia(as defined in Annexure 1), infections like Hepatitis B/C, HIV, syphilis, hypothyroidism and intake of anticonvulsant drugs or any other teratogenic drugs were noted. The maternal and perinatal risk factors were compared between the two groups. For the specific CBDs, relevant investigations including chest X-ray, 2D echocardiography, abdominal ultrasound, cranial ultrasound, MRI- Brain and spine and karyotyping were done. Outcome of each CBD was noted in terms of discharge, expiry and leave against medical advice (LAMA).

\subsection{Sample size}

Taking average prevalence of CBD as $2 \%$ and standard error of $5 \%$, the total number of patients with birth defect would be 31 . Keeping the incidence of CBD in majority of Indian studies as 2 per 100 live births, we would have to screen at least 1600 live neonates for birth defects.

\subsection{Statistical analysis}

SPSS version 10.0 was used for statistical analysis. The results were analyzed using descriptive statistics and making comparisons among the various groups. Discrete (categorical) data were summarized as in proportions and percentages (\%).Chi square test was used to check association between the two categorical variables. Unpaired $t$-test was used to compare means of the two independent groups. The logistic regression analysis was done to find the independent risk factors associated with the CBDs.

\section{Results}

Total 8047 babies were delivered during the study period of 1 year, of which 7,075 were live born and 972 were still born. On screening 7,075 neonates, 92 had 124 CBDs. So the incidence of neonates with CBD was $1.3 \%(92 / 7,075)$.Incidence of CBDs was $124 / 7075$ ie $1.8 \%$. 23 (25\%) neonates had multiple CBDs.

Table 1, shows the baseline characteristics of neonates with CBD. There was male preponderance (1.3:1), most were term (64.1\%) and had a mean gestational age of $36.35 \pm 2.5$ weeks and mean birth weight of $2352.49 \pm 639.4 \mathrm{~g}$.

Maternal baseline characteristics including age, occupation, education, residence and parity showed that mean maternal age of mothers of CBD neonate was $27.67 \pm 6.5$ years. Occupation wise - $70(76.1 \%)$ mothers were housewives, 20 (21.7\%) were doing skilled job and 2 $(2.2 \%)$ were laborers. $69(75 \%)$ mothers with CBD babies were literate and $23(25.0 \%)$ were illiterate. $58(63.0 \%)$ mothers of CBD cases had residence in urban area and $34(37.0 \%)$ in rural area. 41(44.6\%) mothers were primiparous and $51(55.4 \%)$ were multiparous.

The distribution of CBDs on the basis of involving single and multiple systems are shown in Table 2. Out of 92 neonates, 69 (75\%) had isolated CBDs, while 23 (25\%) neonates had CBDs involving more than one system. Among those involving single system, musculoskeletal system was most predominantly involved with 27 cases (29.3\%) followed by central nervous system (17.4\%), cardiovascular system (16.3\%), gastrointestinal system (5.4\%) and genitourinary system (5.4\%). Among 23 neonates with multiple CBDs, there were 21 cases of musculoskeletal system in combination with other systems. The most common combination found was musculoskeletal system with central nervous system (7.6\%). 3 cases involving musculoskeletal, cardiovascular and gastrointestinal were diagnosed later as case of Down syndrome too on karyotying. Table 3 shows the distribution of CBDs along with their ICD-10 classification.

Table 4 shows the bivariate analysis of risk factors. The significant factors were no antenatal visits $(\mathrm{p}=0.041)$, TORCH/VDRL positivity ( $\mathrm{p}$ $=0.023)$, GDM $(\mathrm{p}=0.007)$, hypertension $(\mathrm{p}=0.090)$, parental consanguinity $(p=0.03)$ and no intake of iron/folic acid $(p=0.015)$.These were subjected to multivariate logistic regression analysis.

As shown in Table 5, factors found significant on logistic regression were GDM (OR 3.44; $\mathrm{p}=0.018$ ), maternal hypertension (OR 4.88; $\mathrm{p}=$ 0.011 ), consanguinity (OR 13.55; $\mathrm{p}=0.028$ ) and no intake of iron/folic acid (OR 5.53; $\mathrm{p}=0.001$ ).

Out of 92 neonates with CBDs, 44(47.8\%) babies were discharged, $28(30.5 \%)$ expired and $20(21.7 \%)$ left against medical advice. Among babies with single CBDs, musculoskeletal system has maximum number of discharges (85.2\%). Neonates with CBDs of CNS went LAMA in the highest proportion $(50 \%)$. The neonates with congenital heart defect expired the most (46.7\%). Among the CBDs in combination, the neonate in which GI anomaly was present in combination, had maximum expiry

Table 1

Baseline characteristics of the study subjects.

\begin{tabular}{llll}
\hline $\begin{array}{l}\text { Baseline Neonatal } \\
\text { characteristics }\end{array}$ & $\begin{array}{l}\text { Congenital birth defect } \\
\text { (Cases) } \\
(\mathrm{n}=92)\end{array}$ & $\begin{array}{l}\text { Controls }(\mathrm{n}= \\
92)\end{array}$ & $\begin{array}{l}\mathrm{p}- \\
\text { value }\end{array}$ \\
\hline $\begin{array}{l}\text { Gestational age (weeks) } \\
\quad \text { Mean } \pm \text { SD }\end{array}$ & $36.35 \pm 2.51$ & $36.41 \pm 2.64$ & 0.345 \\
$\begin{array}{l}\text { Birth weight (grams) Mean } \\
\pm \text { SD }\end{array}$ & $2352.49 \pm 639.46$ & $2507.49 \pm$ & 0.831 \\
Male & $51(55.4 \%)$ & 1016.8 & \\
Female & $38(41.3 \%)$ & $42(42.7 \%)$ & 0.064 \\
Ambiguous & $3(3.33 \%)$ & $50(54.3 \%)$ & \\
LSCS & 60 & - & 0.289 \\
NVD & 32 & $65.2 \%$ & \\
\hline
\end{tabular}

Data are represented as mean, $\pm \mathrm{SD}, \mathrm{n}$ and $\% . \mathrm{SD}=$ Standard deviation, $\mathrm{n}=$ number.

LSCS = lower segment cesarean section, NVD = normal vaginal delivery. 
Table 2

System wise distribution of congenital birth defects.

\begin{tabular}{lll}
\hline Anomalies & $\begin{array}{l}\text { Number (n } \\
\text { (92) }\end{array}$ & $\begin{array}{l}\text { Percentage } \\
(\%)\end{array}$ \\
\hline $\begin{array}{l}\text { Single Anomalies (n=69) } \\
\text { Musculoskeletal System }\end{array}$ & 27 & 29.3 \\
Central nervous system & 16 & 17.4 \\
Gastrointestinal System & 5 & 5.4 \\
Cardiovascular system & 15 & 16.3 \\
Genitourinary System & 5 & 5.4 \\
Other Birth Defects & 1 & 1.1 \\
Multiple Anomalies (n=23) & & \\
Musculoskeletal + Central nervous & 7 & 7.6 \\
Musculoskeletal + Gastrointestinal & 4 & 4.3 \\
Musculoskeletal + Cardiovascular & 1 & 1.1 \\
Central nervous + Cardiovascular & 1 & 1.1 \\
Cardiovascular + Genitourinary & 1 & 1.1 \\
Down syndrome involving (Musculoskeletal + & 3 & 3.3 \\
$\quad$ Cardiovascular + Gastrointestinal) & & \\
Musculoskeletal + Central nervous + & 2 & 2.2 \\
$\quad$ Gastrointestinal & & \\
Musculoskeletal + Cardiovascular + & 1.1 \\
$\quad$ Genitourinary & & 3.3 \\
\hline Musculoskeletal + Cardiovascular + Others & 3 &
\end{tabular}

rates ( 3 of 7 ie $42.8 \%$ ).

\section{Discussion}

In our study, incidence of CBDs was $1.3 \%$.Various Indian studies reported a wide range of incidence varying from $0.66 \%$ to $4.08 \% .{ }^{10,11}$ It is because of studies done on live births or included abortion and still birth too. Also it depends on whether the data is collected from general population or a tertiary level hospital. Our incidence is slightly lower than other Indian studies on live births. A recent metaanalysis by Bhide $\mathrm{P}$ et al. found the pooled prevalence of 184.48 per 10,000 births (95\% CI 164.74-204.21).

Marwah et al., Doddabasappa et al. ${ }^{13,14}$ from India reported the incidence of $1.7 \%$ and Sachdeva et al. to be $1.6 \% .{ }^{15}$ A study from North Kerala reported incidence of $0.84 \% .{ }^{16}$ They had low incidence despite the fact they used fetal imaging in antenatal period with clinical examination. Long back, in 1991, a study done by Agarwal et al., in the same region found the incidence of $1.6 \%$ among live births. ${ }^{17}$

In our study, of 92 neonates, $69(75.0 \%)$ had isolated CBDs, while 23 (25.0\%) had involvement of more than one system. Among those involving single system, musculoskeletal system (52.2\%) was the predominant involved system followed by CNS (28.3\%), GIT (26.1\%), CVS (16.3\%) and genitourinary (7.6\%) system. Of 23 neonates with multiple CBDs, most common was musculoskeletal system (91.30\%) in combination with other systems. Our results are supported by similar findings of previous Indian studies. ${ }^{10,18,19}$ Similar to many Indian studies among the musculoskeletal group, CTEV was the commonest CBD (34\%). ${ }^{18}$ Similarly, Devi et al.(2018) also found the most common system to be musculoskeletal system. ${ }^{10}$ Although the most common anomaly found in their study was cleft lip (17.6\%) followed by CTEV (13.2\%).Anomaly wise in our study, CTEV (27.4\%) was most common followed by meningomyelocele and meningocele (11.2\%), cleft palate (6.4\%) and tracheoesophageal fistula (5.6\%).Studies by Marwahetal, Patel et al. reported higher incidence of CNS malformations, ${ }^{13,20}$ whereas Taksande et al., Padmanabhan et al., Patel et al. ${ }^{11,20,21}$ reported CVS malformations as the most common system. CVS defects emerged as the most common CBDs in Pune urban birth defect study (PUBOS) too. ${ }^{23}$ Jayasree et al. from North Kerala found most common system to be urinary system followed by musculoskeletal system(16). Recent metaanalysis compiling large number of Indian studies also showed the result similar to us with CTEV being the most common anomaly followed by anencephaly. ${ }^{12}$

In our study, $25 \%$ babies had multiple defects. In a study by Naseha A
Table 3

Distribution of congenital birth defects along with their ICD-10 classification.

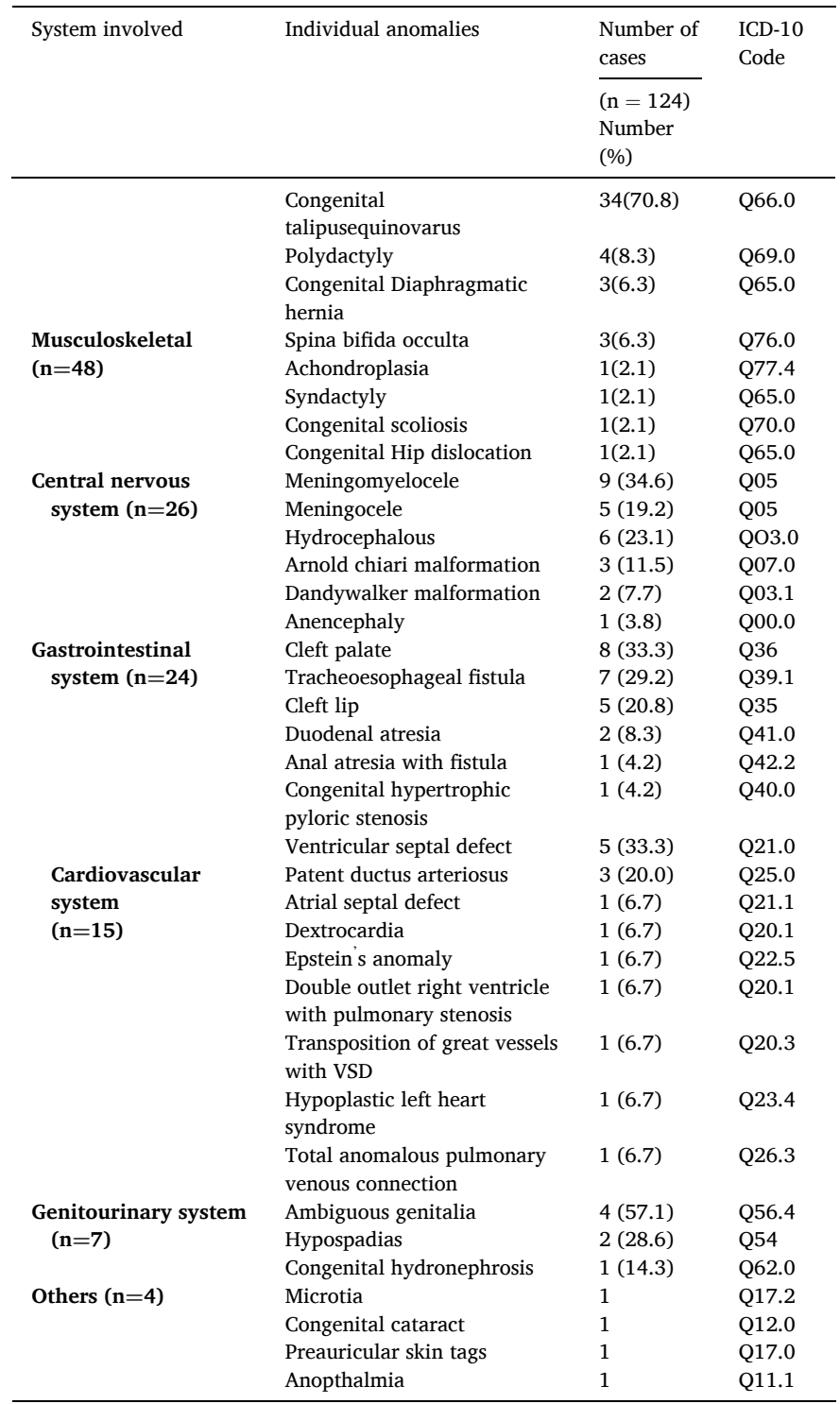

ICD-10- International classification of disease.

Table 4

Distribution of maternal risk factor among the study subjects.

\begin{tabular}{llll}
\hline Risk factors (RF) & CBD case $(\mathrm{n}=92)$ & Controls $(\mathrm{n}=92)$ & p value \\
\hline No antenatal visits & $29(31.5 \%)$ & $17(18.5 \%)$ & $\mathbf{0 . 0 4 1}$ \\
Hypertension & $13(14.1 \%)$ & $6(6.5 \%)$ & 0.090 \\
Bad obstetrical history & $15(16.3 \%)$ & $4(4.3 \%)$ & 0.080 \\
Gestational diabetes & $20(21.7 \%)$ & $7(7.6 \%)$ & $\mathbf{0 . 0 0 7}$ \\
Anemia & $25(27.2 \%)$ & $20(21.7 \%)$ & 0.391 \\
Previous child with CBD & $9(9.8 \%)$ & $2(2.2 \%)$ & $\mathbf{0 . 0 3 0}$ \\
TORCH/VDRL positive & $5(5.4 \%)$ & 0 & $\mathbf{0 . 0 2 3}$ \\
No intake of Iron/Folic acid & $24(26.1 \%)$ & $11(12 \%)$ & $\mathbf{0 . 0 1 5}$ \\
Hypothyroidism & $8(8.7 \%)$ & $7(7.6 \%)$ & 0.788 \\
Consanguinity & $7(7.6 \%)$ & $1(1.1 \%)$ & $\mathbf{0 . 0 3 0}$ \\
IVF conception & $5(5.4 \%)$ & $4(4.3 \%)$ & 0.733 \\
Maternal age $>30$ years & $28(30.4 \%)$ & $23(25 \%)$ & 0.206 \\
Prematurity & $33(35.9 \%)$ & $27(29.3 \%)$ & 0.345 \\
SGA baby & $6(6.5 \%)$ & $10(10.9 \%)$ & 0.523 \\
Male sex & $51(55.4 \%)$ & $42(42.7 \%)$ & 0.064 \\
\hline
\end{tabular}

CBD-congenital birth defect; TORCH- Toxoplasma others Rubella Cytomegalovirus Herpes simplex; VDRL- Venereal disease research laboratory; IVF-In vitro fertilization. 
Table 5

Multivariate Logistic Regression analysis of risk factors for congenital birth defects.

\begin{tabular}{lllll}
\hline Variables & B & SE & p-value & OR \\
\hline No antenatal visits & 0.923 & 0.572 & 0.107 & 2.52 \\
Diabetes mellitus & 1.234 & 0.522 & $\mathbf{0 . 0 1 8}$ & 3.44 \\
Hypertension & 1.585 & 0.620 & $\mathbf{0 . 0 1 1}$ & 4.88 \\
Previous history of CBD & 0.752 & 0.970 & 0.438 & 2.12 \\
TORCH/VDRL positive & 21.038 & 16583.346 & 0.999 & NA \\
Consanguinity & 2.606 & 1.186 & $\mathbf{0 . 0 2 8}$ & 13.55 \\
No intake of Iron/folic acid & 1.710 & 0.537 & $\mathbf{0 . 0 0 1}$ & 5.53 \\
\hline
\end{tabular}

CBD-congenital birth defect; TORCH- Toxoplasma others Rubella Cytomegalovirus Herpes simplex; VDRL- Venereal disease research laboratory.

et al. multiple anomalies were present in $15 \%$ of cases. ${ }^{24}$ High proportion of babies with multiple defects in our study may be due to referral of such high risk pregnant mothers to our center for delivery.

In this most of babies with CBDs were born to mothers of ${ }^{20-30}$ year's age group. Mothers had a mean age of 27 years which represents the usual birth cohort of pregnant women of our hospital. Increased maternal age was not detected as a risk factor in present study. Similar results were shown by Sarkar et al., who found $55.7 \%$ of the CBDs in the 20-30 years. ${ }^{18} \mathrm{Few}$ Indian studies reported a higher incidence of CBDs among mothers aged over 35 years, though it was statistically insignificant. ${ }^{13,15,25}$ So most of the Indian studies have not found any significant association of increased maternal age with the CBDs. In our study, increased parity was also not associated with CBD. Similarly study by Lavanya et al. found that no association with parity. ${ }^{26}$ However few studies like by Marwah et al., Sarkar et al., Sachdeva et al. found multiparous mothers have more cases of CBDs. ${ }^{13,15,18}$ In our study, proportion of caesarean section deliveries were equal among the two groups. Whereas, there are few Indian studies in which higher incidence of malformation was seen in babies born by caesarean section. ${ }^{15,18}$

Among neonatal factors, male babies had slightly higher incidence of malformation $(\mathrm{p}=0.064)$. The findings are supported by many Indian studies. ${ }^{18,21}$ The increased male preponderance might be explained by the fact that still in few parts of India; female babies are considered unwanted pregnancies and are aborted. Contrary to our findings, Sachdeva et al. reported higher incidence of malformation in female babies. ${ }^{15}$ In this study, there was no association of CBDs with low birth weight, prematurity. Most of the babies were term (64.1\%) and had a mean gestational age of 36 weeks. Similar to us, Patel et al. reported that majority of babies with CBD were above $2500 \mathrm{~g}$ (59.9\%) and were appropriate for gestational age with mean weight of $2352.49 \mathrm{~g}^{22}$ Similarly, Padmanabhan et al. found $77 \%$ CBD neonates were term gestation. ${ }^{11}$ Contrary to this Sarkar et al., Marwah et al. reported significant association of prematurity and low birth weight with malformations. ${ }^{13,18}$ Doddabasappa et al. found that risk of preterm birth was higher in pregnancies with multiple congenital anomalies. ${ }^{14}$

In our study, risk factors associated with CBDs were parental consanguinity ( $p$ value $=0.030)$, GDM ( $p$ value $=0.007$ ), TORCH/VDRL infection in mother ( $\mathrm{p}$ value $=0.023$ ), no intake of folic acid during pregnancy $(\mathrm{p}$ value $=0.015)$, no antenatal visit $(\mathrm{p}$ value $=0.041)$ and history of previous CBD ( $\mathrm{p}$ value $=0.030$ ). On multivariate logistic regression, significant risk factors associated with CBD were GDM (OR $=3.44, \mathrm{p}=0.018)$, hypertension $(\mathrm{OR}=4.88, \mathrm{p}=0.011)$, consanguinity $(\mathrm{OR}=13.55, \mathrm{p}=0.028)$ and no intake of folic acid $(\mathrm{OR}=5.53, \mathrm{p}=$ 0.001). A meta-analysis by Ramakrishnan et al. found association of congenital heart disease with hypertension. ${ }^{27}$ We found no association of CBDs with hypothyroidism and in vitro fertilization conception in our study. Sankar et al. reported hypothyroidism as a maternal risk factor for CBDs. ${ }^{28}$ Similar to a recent study we also found significant association with family history of congenital anomalies. ${ }^{29}$ It points towards genetic etiology of CBDs.

Marwahetal, Naseha et al. also reported association between CBDs with bad obstetric history. ${ }^{24,25}$ In our study $16.3 \%$ mothers of CBD cases had bad obstetrical history as compared to $4.3 \%$ in the control mothers. Although it was statistically not significant $(\mathrm{p}=0.08)$. Contrary to this, Cherian et al. found no association with bad obstetrics history. ${ }^{19}$ Similar to Marwah et al., we too did not find association maternal anemia with CBDs. ${ }^{25}$ Stegmann et al. reported TORCH infections to be the most common cause of congenital anomalies(30).We found the association with TORCH in bivariate analysis but not in regression analysis. In the present study, consanguinity was present more among cases $(7.6 \%)$ than $(1.1 \%)$ in controls and was statistically significant $(\mathrm{p}=0.030)$. Association of parental consanguinity has also been reported by Sarkar et al., Singh et al.,Cherian et al. ${ }^{18,19,29}$ Consanguinity promotes homozygosity mapping of the autosomal recessive disorders among carriers which appears in their off springs. In present study, $26.1 \%$ mothersdid not take folic acid compared to $12 \%$ mothers of controls (0.015). This was statistically significant. This was reported as risk factor by Singh et al. too. $^{29}$

In our study, half the neonates with CBDs had poor outcome, $30 \%$ expired and $20 \%$ left against medical advice due to the poor outcome of the defects even after correction. Parents especially of neural tube defect cases wanted to take child LAMA despite adequate counseling. Most deaths were among neonates with critical CVS malformation for which the surgical correction facility in our center does not exist.

There are few limitations in this study. Stillbirths were excluded. Controls were enrolled by enrolling the full-term age and sex-matched healthy control neonate. The data collected from a tertiary care referral hospital is not the true representation of the general population and cannot be extrapolated to the general population. In a resourcelimited setting, genetic workup could not be done. Only for suspected Down's syndrome, the karyotyping could be done. We also admit that there may be recall bias in the risk factor estimation like iron intake, bad obstetrical history. The sample size may be inadequate for risk factor association.

The risk factors found in our study are not new and known for more than a decade, but still the awareness in the general population is poor. In our study the incidence of CBD seems low but its contribution to NMR is high due to large birth cohort. So there is a need to create awareness on clustering of CBDs by preventing consanguineous marriages. Neonates with CVS defects had poor outcome. So they should be transferred in utero to centers where the correction facilities are available. In nutshell providing access to services aimed at CBDs care and prevention should be an important consideration for all governments across the world so as to develop and implement plans to achieve Sustainable Development Goals by the year 2030 .

\section{Declaration of competing interest}

We declare that there is no conflict of interest.

\section{Appendix A. Supplementary data}

Supplementary data to this article can be found online at https://doi. org/10.1016/j.cegh.2022.100999.

\section{References}

1 Christianson A, Howson CP, Modell B. March of Dimes Global Report on Birth Defects: The Hidden Toll of Dying and Disabled Children. White Plains, New York: March of Dimes Birth Defects Foundation; 2006.

2 Mathews TJ, Marian F, Dorman M, Thoma ME. Infant mortality statistics from the 2013 period linked birth/infant death data set. Natl Vital Stat Rep. August 6, 2015;64 (No. 9).

3 India State-Level Disease Burden Initiative Child Mortality Collaborators. Subnational mapping of under-5 and neonatal mortality trends in India: the global burden of disease study 2000-17. Lancet. 2020 May 23;395(10237):1640-1658. https://doi.org/10.1016/S0140-6736(20)30471-2. Epub 2020 May 12. PMID: 32413293; PMCID: PMC7262604.

4 The state of the world's children 2015: executive Summary. Available at https ://www.unicef.org/publications/files/SOWC_2015_Summary_and_Tables.pdf. 
5 Ujagare D, Kar A. Birth defect mortality in India 1990-2017: estimates from the Global Burden of Disease data. J Community Genet. 2021;12(1):81-90. https://doi. org/10.1007/s12687-020-00487-z.

6 Liu L, Oza S, Hogan D, et al. Global, regional, and national causes of child mortality in 2000-13, with projections to inform post-2015 priorities: an updated systematic analysis. Lancet. 2015;385(9966):430-440.

7 Birth defects in south-east asia. Available at https://www.who.int/southeastasi a/health-topics/birth-defects.

8 International Institute for Population Sciences (IIPS). Macro International National Family Health Survey (NFHS-3), 2005-06. vol. 1. India: IIPS; 2007. Mumbai.

9 International classification of disease-10. Available at https://icd.who.int/browse1 0/2019/en.

10 Devi KR, Praneshwari Devi RK, Priya J, Sanaton A, Singh LR, Murray L. A study of congenital anomalies in a tertiary care hospital in North East region, India. Int $J$ ReprodContraceptObstetGynecol. 2018;7:2899-2903.

11 Padmanabhan R, Venkatasubramanian R, Heber A. Prevalence and pattern of congenital malformations among neonates in a medical college hospital - a retrospective study. Int J Sci Stud. 2019;6(12):28-31.

12 Bhide P, Kar A. A national estimate of the birth prevalence of congenital anomalies in India: systematic review and meta-analysis. BMC Pediatr. 2018;18(1):175. https:// doi.org/10.1186/s12887-018-1149-0. Published 2018 May 25.

13 Marwah A. Profile of gross congenital malformations among live newborns and its associated risk factors from a tertiary care rural teaching institute. Asian J Biomed Pharm Sci. 2016;6(55):16.

14 Doddabasappa PN, Adarsh E, Divya N. Prevalence of congenital anomalies: a hospital-based study. Int J ContempPediatr. 2018;5:119-123.

15 Sachdeva S, Nanda S, Bhalla K, Sachdeva R. Gross congenital malformation at birth in a government hospital. Indian J Publ Health. 2014;58:54-56.

16 Jayasree S, D'Couth S. Prevalence of congenital anomalies in a tertiary care centre in North Kerala, India. Int J ReprodContraceptObstetGynecol. 2018;7:864-869.

17 Agarwal SS, Singh U, Singh PS, et al. Prevalence \& spectrum of congenita malformations in a prospective study at a teaching hospital. Indian J Med Res. 1991; 94:413-419.
18 Sarkar S, Patra C, Dasgupta MK, Nayek K, Karmakar PR. Prevalence of congenital anomalies in neonates and associated risk factors in a tertiary care hospital in eastern India. J ClinNeonatol. 2013;2:131.

19 Cherian A, Jamkhandi D, George K, Bose A, Prasad J, Minz S. Prevalence of congenital anomalies in a secondary care hospital in south India: a cross-sectional study. J Trop Pediatr. 2016;62:361-367.

20 Patel ZM, Adhia RA. Birth defects surveillance study. Indian J Pediatr. 2005 Jun;72 (6):489-491. https://doi.org/10.1007/BF02724426. PMID: 15985737.

21 TaksandeA VihekarK, ChaturvediP JainM. Congenital malformations at birth in Central India: a rural medical college hospital based study. Indian J Hum Genet. 2010; 16(3):159-163.

22 Patel KG, Chaudhary C. Study of congenital malformations in newborns: a hospital based prospective study. Int J ContempPediatr. 2017;4:1409-1413.

23 Bhide P, Gund P, Kar A. Prevalence of congenital anomalies in an Indian maternal cohort: healthcare, prevention, and surveillance implications. PLoS One. 2016;11 (11), e0166408.

24 Naseha A, Iqbal Y. Incidence of congenital anomalies in tertiary health care centre. J. Evolution Med. Dent. Sci. 2016;5(67):4826-4833.

25 Marwah S, Sharma S, Kaur H, Gupta M, Goraya SPS. Surveillance of congenital malformations and their possible risk factors in a teaching hospital in Punjab. Int $J$ ReprodContraceptObstetGynecol. 2014;3:162-167.

26 Lavanya S, Seethalakshmi V. A two-year study of patterns and prevalence of congenital malformations. Int J ReprodContraceptObstetGynecol. 2018;7:114-118.

27 Ramakrishnan A, Lee L, Mitchell L, Agopian A. Maternal hypertension during pregnancy and the risk of congenital heart defects in offspring: a systematic review and meta-analysis. Pediatr Cardiol. 2015;36(7):1442-1451.

28 Sankar VH, Uma T, George S, et al. Pattern of congenital abnormalities in a tertiary hospital and its impact on neonatal mortality. Indian J Child Health. 2017;4(4): 599-602.

29 Singh A, Sinha S. Risk factors of congenital malformations in North India: a case control study. J Postgrad Med Educ Res. 2016;50(1):22-27.

30 Stegmann BJ, Carey JC. TORCH infections. Toxoplasmosis, other (syphilis, varicellazoster, parvovirus B19), Rubella, cytomegalovirus (CMV), and herpes infections. Curr Wom Health Rep. 2002;2(4):253-258. 